\title{
shRNA-mediated RPS15A silencing inhibits U937 acute myeloid leukemia cell proliferation and enhances apoptosis
}

\author{
GUANGYAO LI ${ }^{1,2}$, LI ZHANG ${ }^{2}$, JIZHU LIU ${ }^{2}$, TAIWU XIAO ${ }^{2}$, GUOZHEN LIU $^{2}$, JINGXIA WANG ${ }^{2}$ and MING HOU ${ }^{1}$ \\ ${ }^{1}$ Department of Hematology, Qilu Hospital of Shandong University, Jinan, Shandong 250012; \\ ${ }^{2}$ Department of Hematology, Liaocheng People's Hospital, Liaocheng, Shandong 252000, P.R. China
}

Received April 10, 2015; Accepted March 7, 2016

DOI: $10.3892 / \mathrm{mmr} .2016 .5064$

\begin{abstract}
Ribosomal protein S15a (RPS15A), which is a component of the $40 \mathrm{~S}$ ribosomal subunit, is able to promote mRNA/ribosome interaction during the early stage of translation. Previous studies have demonstrated that RPS15A regulates cell growth and is involved in several types of human cancer. The aim of the present study was to investigate the role of RPS15A in acute myeloid leukemia (AML). Lentivirus-delivered short hairpin RNA (shRNA) was used to silence RPS15A expression in the U937 AML cell line. Subsequently, the effects of RPS15A silencing on cell viability, cell cycle progression and apoptosis were investigated. The results indicated that RPS15A knockdown significantly inhibited cell growth. Furthermore, flow cytometric analysis demonstrated that the majority of U937 cells were arrested in $\mathrm{G}_{0} / \mathrm{G}_{1}$ phase and sub- $\mathrm{G}_{1}$ phase after RPS15A knockdown, as determined using propidium iodide staining. In addition, U937 cells underwent apoptosis in response to RPS15A silencing, as determined using Annexin V/7-aminoactinomycin D staining. In conclusion, the present study provides novel evidence indicating that RPS15A modulates AML cell growth in vitro, and may be considered a novel therapeutic target for the treatment of AML.
\end{abstract}

\section{Introduction}

Leukemia is the most common malignancy in children (0-14 years) and young adults (15-39 years). According to GLOBOCAN 2012 data, 351,965 new cases of leukemia were diagnosed in 2012 (2.5\% of total cancer cases), and leukemia accounts for $\sim 265,471$ cases of cancer-associated mortality worldwide every year. Among these newly diagnosed cases, $30 \%(105,436 / 351,965$ cases $)$ occurred in the USA and

Correspondence to: Dr Ming Hou, Department of Hematology, Qilu Hospital of Shandong University, 107 Wenhua Xi Road, Jinan, Shandong 250012, P.R. China

E-mail: hou21ming@163.com

Key words: acute myeloid leukemia, shRNA, ribosomal protein S15a, proliferation, apoptosis
China (1). In addition, leukemia has the highest incidence and mortality rate of any cancer in children in China. The majority of cases of leukemia are acute myeloid leukemia (AML). AML represents a heterogeneous hematological malignancy characterized by uncontrollable proliferation and survival, and impaired differentiation of neoplastic cells or blasts (2). In the USA, 19,950 cases of AML and 10,430 cases of AML-associated mortality are projected in 2016 (3). AML is often fatal, due to the following reasons: Firstly, the majority of cases of AML initially respond to traditional chemotherapy (4); however, relapse is common indicating resistance of malignant cells to chemotherapy (4-7); and secondly, the acuity and severity of AML is often poor at diagnosis. Recently, studies have focused on identifying novel genes, which target tumor cell growth and survival signaling pathways (8-11). Identification of these genes may provide a novel strategy for the optimization of AML therapy or diagnosis (12).

The ribosome is comprised of two ribonucleoprotein subunits: 40S and 60S, which are known as the 'small' and 'large' subunits, respectively. It has previously been reported that ribosomal proteins exhibit extra-ribosomal functions, which include, but are not limited to, DNA repair, cell death, inflammation, tumorigenesis and transcriptional regulation (13). Ribosomal protein S15a (RPS15A), which is a component of the $40 \mathrm{~S}$ ribosomal subunit, is able to promote mRNA/ribosome interaction during the early stage of translation. RPS15A has been shown to suppress the cdc33 mutation growth arrest phenotype by binding and stabilizing eukaryotic initiation factor 4E (14), thus indicating that RPS15A has a function in cell growth regulation. In addition, RPS15A has been identified as a novel internal control gene for use in quantitative polymerase chain reaction (qPCR) analysis of prepubertal bovine mammary tissue (15). Akiyama et al (16) demonstrated that RPS15A is upregulated in response to transforming growth factor- $\beta$ in the A549 human lung carcinoma cell line, which has a central role in the regulation of proliferation, differentiation, apoptosis and carcinogenesis. Furthermore, Zeller et al (17) identified RPS15A as a responsive gene of the Myc oncogenic transcription factor. Krüppel-like factor 4 is a tumor suppressor (18), which is able to inhibit the GC content of the RPS15A promoter to downregulate its expression (19). In addition, RPS15A was shown to be overexpressed in hepatitis B virus-encoded $\mathrm{X}$ antigen-positive cells, 
and overexpression of RPS15A stimulated cell growth, colony formation and tumor formation in SCID mice in vivo (20), thus indicating that RPS15A may have a key role in hepatocellular carcinogenesis. A meta-analysis of cancer gene expression signatures revealed that RPS15A is highly expressed in astrocytoma, colorectal cancer and prostate cancer (21).

Despite reports indicating that RPS15A may stimulate growth in yeast, plants and human cancer (22), its functional role in AML remains unknown. The present study demonstrated that knockdown of RPS15A by lentivirus-mediated short hairpin RNA (shRNA) was able to inhibit AML cell proliferation and induce apoptosis in vitro. Furthermore, RPS15A knockdown suppressed cell cycle progression via $\mathrm{G}_{0} / \mathrm{G}_{1}$ phase arrest. Collectively, RPS15A may modulate AML cell growth and have a prominent role in AML; therefore, RPS15A may be considered a potential therapeutic target for the treatment of AML.

\section{Materials and methods}

Cell lines and culture conditions. Human embryonic kidney 293T (HEK 293T) cells were cultured in Dulbecco's modified Eagle's medium (Hyclone; GE Healthcare Life Sciences, Logan, UT, USA) supplemented with $10 \%$ fetal bovine serum (FBS; Biowest SAS, Nuaillé, France). Human acute myeloid leukemia (AML) U937 cells were cultured in RPMI-1640 (Hyclone; GE Healthcare Life Sciences) supplemented with $10 \%$ FBS. The cell lines were purchased from the Cell Bank of Chinese Academy of Science (Shanghai, China), and were maintained at $37^{\circ} \mathrm{C}$ in a humidified incubator containing $5 \%$ $\mathrm{CO}_{2}$.

Preparation of shRNA-expressing lentiviruses and cell infection. Two targeted sequences (S1, S2) designed to be homologous to RPS15A were cloned into the lentiviral expression vector pFH-L (Shanghai Hollybio, Shanghai, China), which was digested by NheI and PacI restriction enzymes (Takara Bio, Inc., Otsu, Japan). The sequences of the two shRNA targeting RPS15A were as follows: S1, 5'-GTGCAACTC AAAGACCTGGAACTCGAGTTCCAGGTCTTTGAGTTG CACTTTTT-3' and S2, 5'-GCATGGTTACATTGGCGA ATTCTCGAGAATTCGCCAATGTAACCATGCTTTTT-3' (Shanghai Hollybio). The lentiviruses containing S1 and S2 sequences were classified as Lv-shRPS15A (S1) and Lv-shRPS15A (S2), respectively. As a negative control, a scrambled shRNA was used (Shanghai Hollybio), which had the following sequence: 5'-GCGGAGGGTTGAAAGAATATC TCGAGATATTCTTTCAAACCCTCCGCTTTTTT-3'. This sequence was classified as Lv-shCon. The uninfected control cells were classified as Con. Each single-stranded oligonucleotide became a double-stranded oligonucleotide using an annealing system. Briefly, the annealing reaction mixture, containing $5 \mu \mathrm{l}$ each of forward and reverse primers (Shanghai Hollybio), $10 \mu 15 \mathrm{X}$ annealing buffer (Beyotime Institute of Biotechnology, Shanghai, China) and $30 \mu 1$ double-distilled $\mathrm{H}_{2} \mathrm{O}\left(\mathrm{ddH}_{2} \mathrm{O}\right)$, was run on a Bioer TC-96/G/H(b)A (BIOER, Hangzhou, China) thermal cycler with the following program: Initial denaturation at $94^{\circ} \mathrm{C}$ for $1 \mathrm{~min}$, followed by 50 cycles of denaturation at $80^{\circ} \mathrm{C}$ for $30 \mathrm{sec}$ and extension at $30^{\circ} \mathrm{C}$ for $30 \mathrm{sec}$, followed by cooling to $4^{\circ} \mathrm{C}$ at the end of the PCR.
Subsequently, the double-stranded oligonucleotide was cloned into the linearized $\mathrm{pFH}-\mathrm{L}$ vector.

The ligation product was used to transform the Escherichia coli DH5 $\alpha$ strain, and was extracted using a plasmid purification kit [Tiangen Biotech (Beijing) Co., Ltd., Beijing, China]. The plasmid was confirmed by PCR and sequencing. The shRNA-expressing lentiviruses were produced by co-transfection of $10 \mu \mathrm{g}$ recombinant expression shRNA vectors and packaging pHelper plasmids $(7.5 \mu \mathrm{g}$ pVSVG-I and $5 \mu \mathrm{g}$ pCMV $\Delta$ R8.92; Shanghai Hollybio) into the HEK 293T cells using Lipofectamine 2000 (Invitrogen; Thermo Fisher Scientific, Inc., Waltham, MA, USA), according to the manufacturer's protocol. Supernatants containing either the lentivirus expressing the RPS15A shRNA or the control shRNA were harvested 24,48 and $72 \mathrm{~h}$ post-transfection. The lentiviruses were purified using ultracentrifugation, and the titer of the lentiviruses was determined as previously described (23). U937 cells were infected with the concentrated virus at a multiplicity of infection of 80 and mock-infected cells were used as negative controls. After $96 \mathrm{~h}$ of infection, the expression of green fluorescent protein was observed using a fluorescent microscope (CKX41; Olympus Corporation, Tokyo, Japan) in order to assess the infection efficiency. The efficiency of RPS15A knockdown was evaluated by reverse transcription (RT)-qPCR and western blot analysis.

RNA isolation and RT-qPCR. U937 cells were harvested 5 days post-lentiviral infection. Total RNA was extracted using TRIzol ${ }^{\circledR}$ reagent (Invitrogen; Thermo Fisher Scientific, Inc.), according to the manufacturer's protocol. The purity and integrity of the RNA was assessed by spectrophotometry (Epoch Microplate Spectrophotometer; Biotek Instruments, Inc., Winooski, VT, USA) and 3\% agarose gel electrophoresis, respectively. First-strand cDNA was synthesized from $2 \mu \mathrm{g}$ total RNA using RT reagents containing $1 \mu \mathrm{l}$ Oligo dT $(0.5 \mu \mathrm{g} / \mu \mathrm{l}), 4 \mu \mathrm{l}$ M-MLV Buffer, $1.25 \mu \mathrm{l}$ dNTPs, $0.5 \mu \mathrm{l}$ RNasin, $0.75 \mu \mathrm{l}$ M-MLV-RTase and Nuclease-free water, to a final volume of $20 \mu \mathrm{l}$ (Promega Corporation, Madison, WI, USA). PCR primers (Shanghai Hollybio) were designed to amplify fragments that span intron/exon boundaries and the sequences were as follow: RPS15A, forward 5'-TGACGTGCAACTCAA AGACC-3', reverse 5'-CCAGAGTCCATGAGGCATT-3'; $\beta$-actin, forward 5'-GTGGACATCCGCAAAGAC-3', and reverse 5'-AAAGGGTGTAACGCAACTA-3'. RT-qPCR was performed in the linear range using the SYBR Green Core Reagents kit (Takara Bio, Inc.) on a Bio-Rad CFX96 Touch ${ }^{\mathrm{TM}}$ Real-Time PCR system (Bio-Rad Laboratories, Inc., Hercules, CA, USA). The PCR reaction mixture consisted of $5 \mu \mathrm{l}$ cDNA, $10 \mu 1$ XX SYBR Premix Ex Taq (Takara Bio, Inc.), $0.8 \mu 1$ PCR

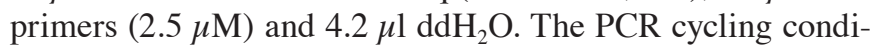
tions were as follows: Initial denaturation at $95^{\circ} \mathrm{C}$ for $60 \mathrm{sec}$, 45 cycles of denaturation at $95^{\circ} \mathrm{C}$ for $5 \mathrm{sec}$, annealing and extension at $60^{\circ} \mathrm{C}$ for $20 \mathrm{sec}$, followed by cooling to $4^{\circ} \mathrm{C}$. The absorbance values were read at the extension stage. $\beta$-actin was used as the internal control for all normalizations and the relative expression levels were calculated using the $2^{-\Delta \Delta \mathrm{C}}$ method (24).

Western blot analysis. U937 cells were harvested 5 days post-lentiviral infection, were washed twice with ice-cold 
phosphate-buffered saline (PBS), and were lysed in ice-cold 2x sodium dodecyl sulfate (SDS) Lysis Buffer [100 mM Tris- $\mathrm{HCl}$ (pH 6.8), 10 mM EDTA, 4\% SDS, 10\% Glycine]. The protein concentration of the cell lysates was determined using the bicinchoninic acid protein assay kit (Thermo Scientific Pierce, Rockford, IL, USA). Total protein samples $(30 \mu \mathrm{g})$ were separated by $10 \%$ SDS-polyacrylamide gel electrophoresis and were transferred onto nitrocellulose membranes. The membranes were blocked with Tris-buffered saline and Tween 20 (Sigma-Aldrich, St. Louis, MO, USA) containing 5\% non-fat milk at room temperature for $2 \mathrm{~h}$, after which they were incubated with the following antibodies: Anti-RPS15A (1:1,000; cat. no. AP4804a; Abgent, San Diego, CA, USA) and anti-glyceraldehyde 3-phosphate dehydrogenase (GAPDH) (1:40,000; cat. no. 10494-1-AP; Proteintech Group, Inc., Chicago, IL, USA) at $4^{\circ} \mathrm{C}$ overnight. Subsequently, the membranes were incubated with horseradish peroxidase-conjugated goat anti-rabbit secondary antibodies (1:5,000; cat. no. sc-2054; Santa Cruz Biotechnology, Inc., Dallas, TX, USA). Signals were detected using an enhanced chemiluminescence test kit (Amersham; GE Healthcare Life Sciences, Chalfont, UK). GAPDH served as the internal standard. Density analysis was performed using Quantity One software, version 4.62 (Bio-Rad Laboratories, Inc.).

3-(4,5-dimethylthiazol-2-yl)-2,5-diphenyltetrazolium bromide (MTT) assay-growth curve. In vitro cell viability was analyzed using the MTT assay. U937 cells were seeded at a density of 3,500 cells/well in 96-well plates $96 \mathrm{~h}$ post-lentiviral infection. After $24 \mathrm{~h}, 20 \mu 15 \mathrm{mg} / \mathrm{ml}$ MTT solution (Sigma-Aldrich) was added to each well daily between days 1 and 5 , and the plates were incubated for $4 \mathrm{~h}$ at $37^{\circ} \mathrm{C}$. Subsequently, $100 \mu 1$ stop buffer $(0.012 \mathrm{M} \mathrm{HCl}, 10 \% \mathrm{SDS}, 5 \%$ isopropanol) was added to each well and gently agitated for $10 \mathrm{~min}$. Absorbance values were measured at a wavelength of $595 \mathrm{~nm}$ using the Epoch Microplate Spectrophotometer.

Cell cycle analysis. To determine cell cycle distribution, $8 \times 10^{4} \mathrm{U} 937$ cells were seeded in $6 \mathrm{~cm}$ dishes a total of 6 days after lentiviral infection. Following a $40 \mathrm{~h}$ culture, the cells were washed twice with ice-cold PBS and were resuspended in PBS containing $50 \mu \mathrm{g} / \mathrm{ml}$ RNase A (Sigma-Aldrich) and $50 \mu \mathrm{g} / \mathrm{ml}$ propidium iodide (Sigma-Aldrich). Cells were incubated at $37^{\circ} \mathrm{C}$ in the dark for $1 \mathrm{~h}$. The percentage of cells in each phase of the cell cycle was measured using FACScan (BD Biosciences, San Diego, CA, USA) and results were analyzed using ModFit software, version 3.2 (Verity Software House, Topsham, ME, USA).

Apoptosis analysis. To assess the apoptotic rate, $1 \times 10^{5} \mathrm{U} 937$ cells were seeded in $6 \mathrm{~cm}$ dishes. Apoptosis was detected 6 days following lentiviral infection. Cells were harvested and the experiment was conducted according to the Annexin V-allophycocyanin (APC)/7-aminoactinomycin D (7-AAD) Apoptosis Assay kit (Nanjing KeyGen Biotech Co., Ltd., Nanjing, China). A total of $1 \times 10^{6}$ cells were resuspended in $100 \mu \mathrm{l} 1 \mathrm{X}$ Annexin $\mathrm{V}$ binding buffer with $5 \mu \mathrm{l}$ Annexin V-APC and $5 \mu 1$ 7-AAD and were incubated for $15 \mathrm{~min}$ at room temperature in the dark. The cells were analyzed on a FACSCalibur (BD Biosciences) using CellQuest Pro software
(BD Biosciences). The percentage of each quadrant was calculated.

Statistical analysis. Results are presented as the mean \pm standard deviation. Differences between the groups were assessed using the Student's t-test. $\mathrm{P}<0.05$ was considered to indicate a statistically significant difference. Statistical analyses were performed using SPSS 13.0 statistical software (SPSS, Inc., Chicago, IL, USA).

\section{Results}

Lentivirus-mediated shRNA inhibits the expression of RPS15A in U937 cells. The U937 cell line was infected with shCon, shRPS15A (S1) and shRPS15A (S2) lentiviral particles. Infection efficiency was $>70 \%$, as determined by detecting the expression of green fluorescent protein $96 \mathrm{~h}$ post-infection (Fig. 1A).qPCR analysis demonstrated that the RPS15A mRNA expression levels were significantly reduced in the shRPS15A (S1; $\mathrm{P}<0.001)$ and shRPS15A ( 2 2; $\mathrm{P}<0.001)$ groups compared with the shCon and control groups (Fig. 1B). The protein expression levels of RPS15A were also markedly decreased in the shRPS15A (S1) and shRPS15A (S2) groups compared with the shCon and control groups (Fig. 1C). The RPS15A knockdown efficacy of shRPS15A (S1) and shRPS15A (S2) was 96.0 and $93.2 \%$, respectively. These results suggest that lentivirus-mediated shRNA knockdown of RPS15A expression was specific, and the off-target effects were eliminated. These results indicate that lentivirus-mediated RPS15A shRNA was able to significantly downregulate RPS15A expression in U937 cells.

Knockdown of RPS15A inhibits proliferation of U937 cells. To examine the effects of RPS15A knockdown on U937 cell growth, shRPS15A (S1)-, shRPS15A (S2)- and shCon-infected U937 cells were subjected to the MTT assay. As shown in Fig. 2, cell proliferation in the shRPS15A (S1) and shRPS15A (S2) groups was significantly reduced; proliferation decreased by $>80 \%$ in the shRPS15A ( $\mathrm{S} 1)$ group $(\mathrm{P}<0.001)$ and by $>84.5 \%$ in the shRPS15A (S2) group ( $<<0.001$; Fig. 2$)$ at days 4 or 5. Since proliferation inhibition occurred to a greater extent in the shRPS15A (S2) group, these cells were selected for further experimentation. Notably, the proliferative index [proliferative index $\left.=\left(S+G_{2} / M\right) /\left(G_{0} / G_{1}+S+G_{2} / M\right)\right]$ of shRPS15A (S2)-transduced U937 cells was slightly lower than that of the shCon and control cells $(35.45 \pm 3.2$ vs. $50 \pm 3.8$ and $51.3 \pm 4.2 \%$; data from Fig. 3). These results indicate that the proliferation of U937 cells was significantly inhibited following RPS15A knockdown compared with in the shCon and control groups.

Knockdown of RPS15A arrests cell cycle progression of U937 cells. To investigate whether cell cycle arrest contributed to growth inhibition, flow cytometric analysis was conducted. The proportion of cells in $G_{0} / G_{1}$ phase was significantly increased $(\mathrm{P}<0.001)$, and the percentage of cells in $\mathrm{S}$ phase were significantly decreased $(\mathrm{P}<0.001)$, in the shRPS15A (S2) group compared with the shCon and control groups (Fig. 3A and B). These results indicate that shRPS15A (S2)-induced growth suppression may be partly mediated by cell cycle arrest at $G_{0} / G_{1}$ phase. In addition, the proportion of cells in 
A

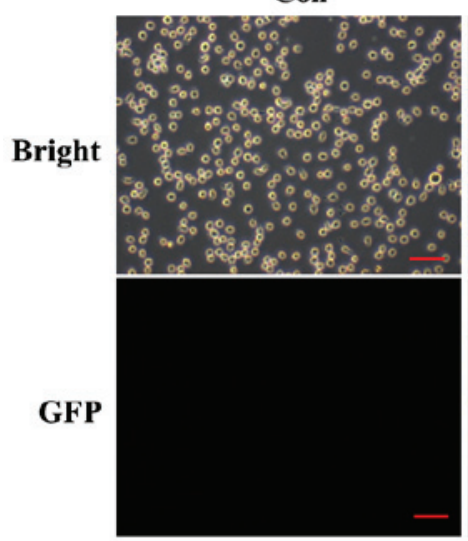

B

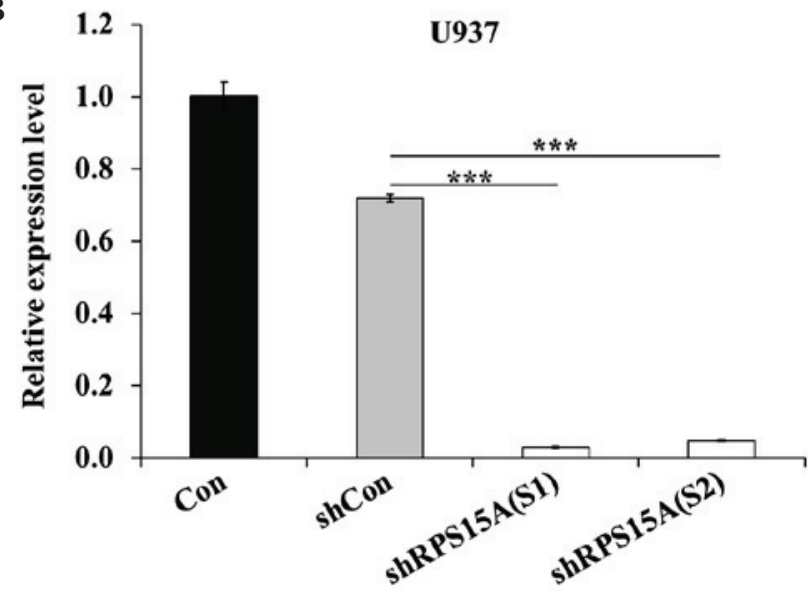

shCon

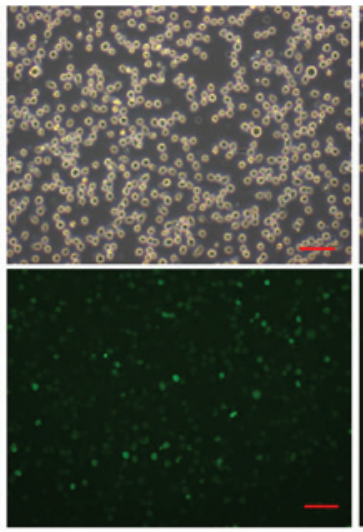

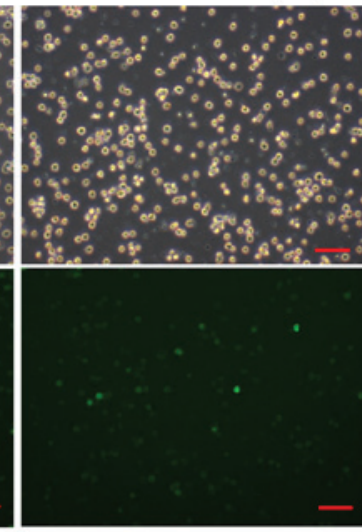

C

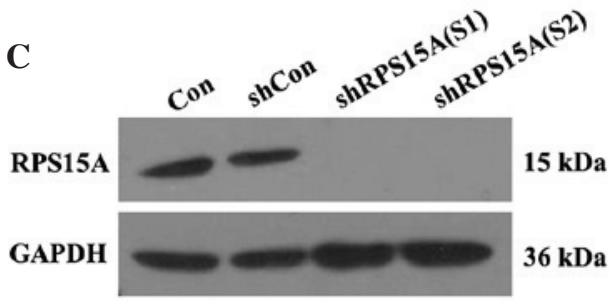

Figure 1. Knockdown of ribosomal protein S15a (RPS15A) in U937 cells by lentivirus-delivered short hairpin RNA (sh)RPS15A (S1)/(S2). (A) Detection of lentiviral infection efficiency. The U937 cells were infected with shCon, shRPS15A (S1) or shRPS15A (S2), or remained uninfected (control; Con). Bright (upper panel) or green fluorescent protein (GFP) (lower panel) images were obtained $96 \mathrm{~h}$ post-infection. Scale bar, $100 \mu \mathrm{m}$. (B) Analysis of RPS15A mRNA expression in U937 cells transduced with shCon, shRPS15A (S1) or shRPS15A (S2) by quantitative polymerase chain reaction. (C) Western blot analysis of RPS15A protein expression in U937 cells transduced with shCon, shRPS15A (S1) or shRPS15A (S2). Data are presented as the mean \pm standard deviation of three independent experiments. ${ }^{* * *} \mathrm{P}<0.001$, compared with the shCon group. GAPDH, glyceraldehyde 3-phosphate dehydrogenase.

sub- $\mathrm{G}_{1}$ was significantly increased in the shRPS15A (S2) group compared with the shCon and control groups $(\mathrm{P}<0.001$; Fig. 3C).

Knockdown of RPS15A enhances apoptosis of U937 cells. Results of the flow cytometric analysis indicated that the percentage of early apoptotic (Annexin V-positive/7-AAD-negative) and late apoptotic (Annexin V-positive/7-AAD-positive) cells was significantly higher in the shRPS15A (S2)-transduced cells compared with in the shCon and control cells $(\mathrm{P}<0.001$; Fig. 4A and B). Following transduction, the apoptotic rate (early and late apoptotic cells) of U937 cells in the shRPS15A (S2) group was $18.35 \pm 0.28 \%$, which was significantly higher than in the shCon and control groups (7.97 \pm 0.12 and $8.2 \pm 0.06 \%)$. The apoptotic rate of U937 cells was significantly increased following RPS15A knockdown, as compared with that in the shCon and control groups.

\section{Discussion}

AML has the lowest survival rate among all types of leukemia (25), and knowledge regarding its basic biology remains to be completely elucidated. Numerous molecules have



Figure 2. Knockdown of ribosomal protein S15a (RPS15A) inhibits the growth of U937 cells in vitro. Growth curves of control (Con), short hairpin RNA (sh)Con, shRPS15A (S1) and shRPS15A (S2) groups, as measured by 3-(4,5-dimethylthiazol-2-yl)-2,5-diphenyltetrazolium bromide assay. Data are presented as the mean \pm standard deviation of three independent experiments. ${ }^{* * * *} \mathrm{P}<0.001$, compared with the shCon group. OD, optical density.

been identified as potential targets; however, only a few have pivotal roles in AML cell proliferation and survival (12,26-33). 

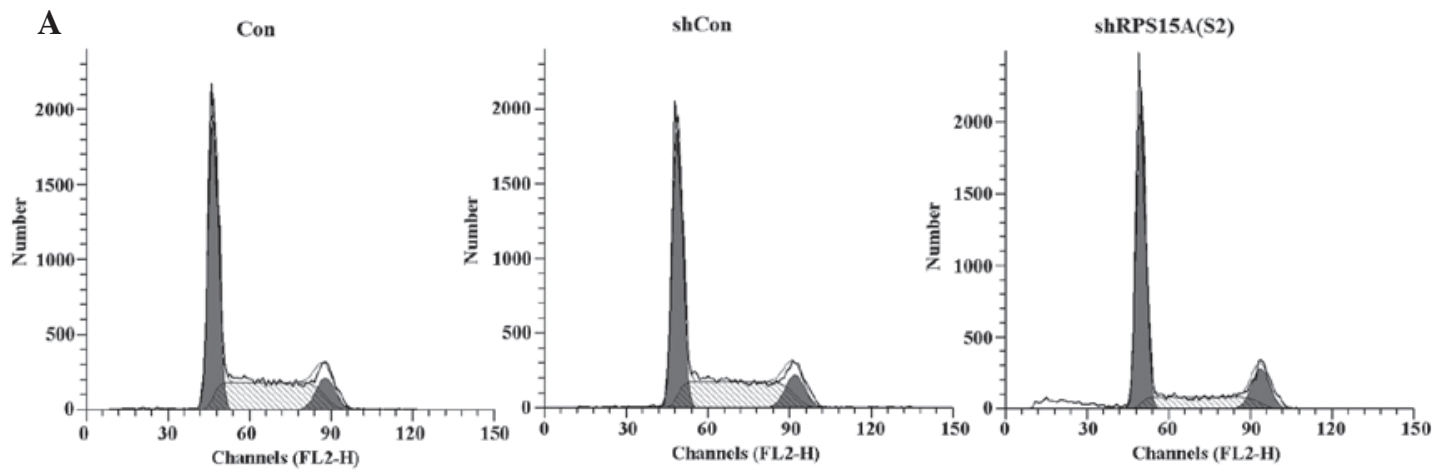

B

U937

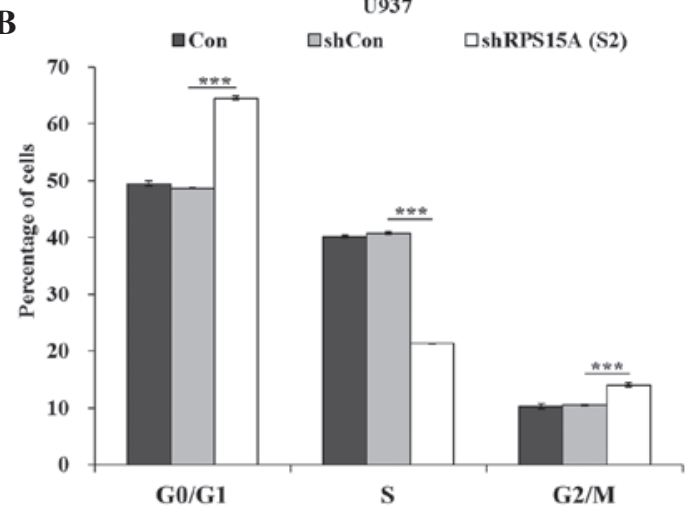

C

U937

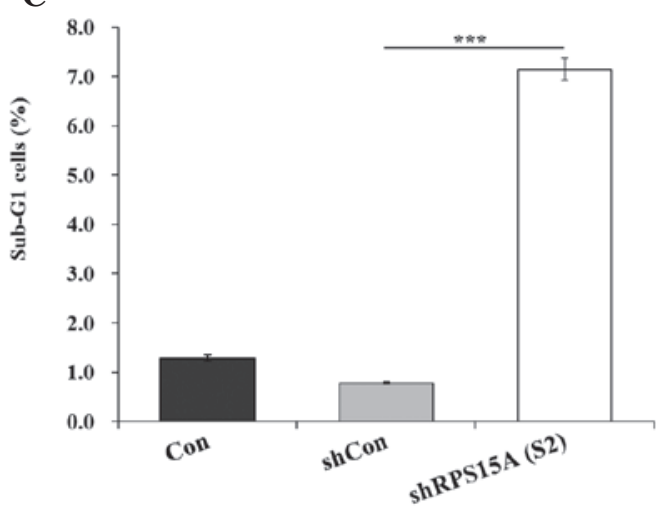

Figure 3. Knockdown of ribosomal protein S15a (RPS15A) blocks cell cycle progression of U937 cells. Cell cycle distribution was analyzed by flow cytometry. (A) Representative images of control (Con), short hairpin RNA (sh)Con and shRPS15A (S2) cell cycle progression, as determined by flow cytometric analysis. (B) Proportion of cells in different cell cycle phases. (C) Proportion of cells in sub $-\mathrm{G}_{1}$. Data are presented as the mean \pm standard deviation of three independent experiments. ${ }^{* * *} \mathrm{P}<0.001$, compared with the shCon group.
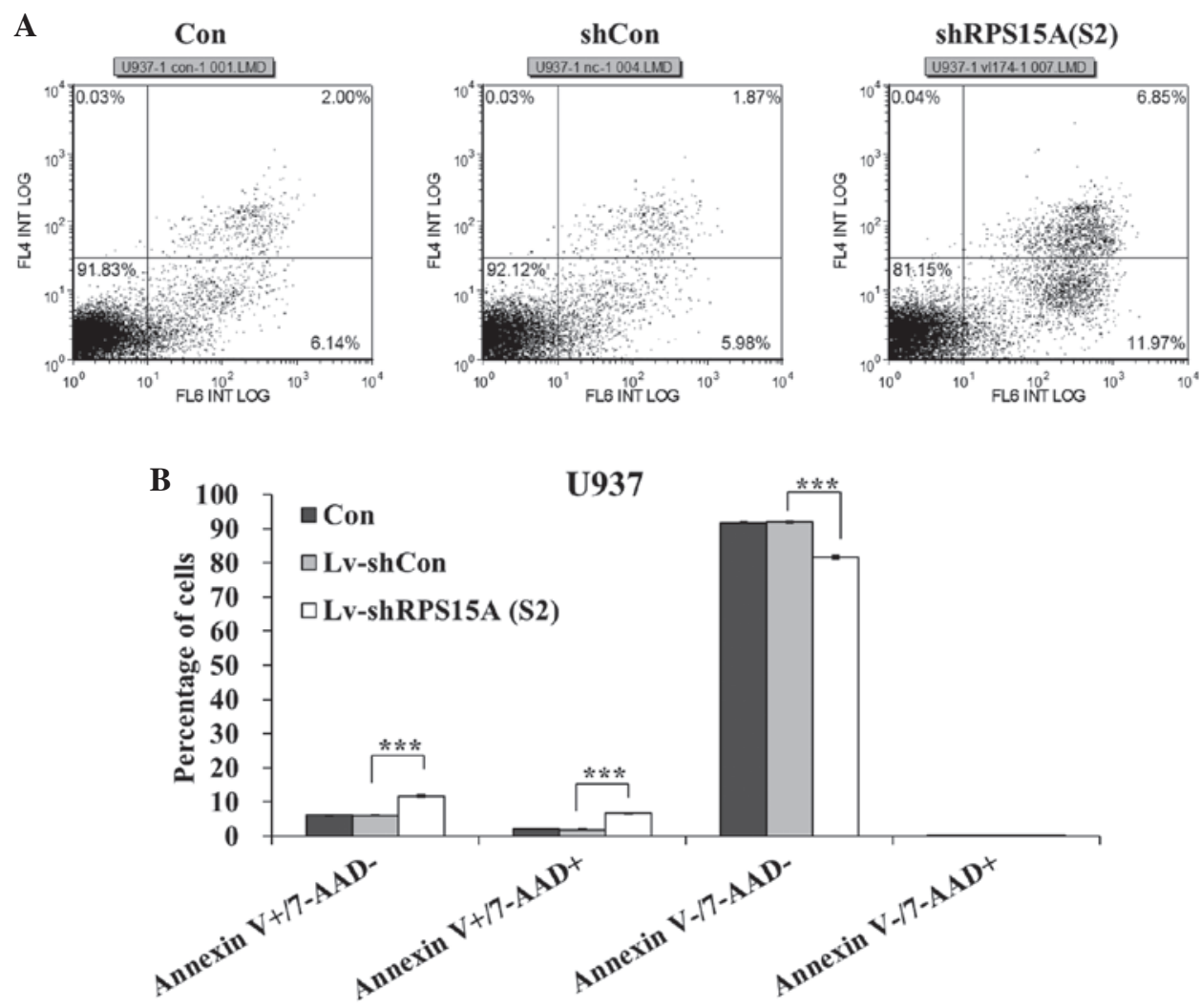

U937

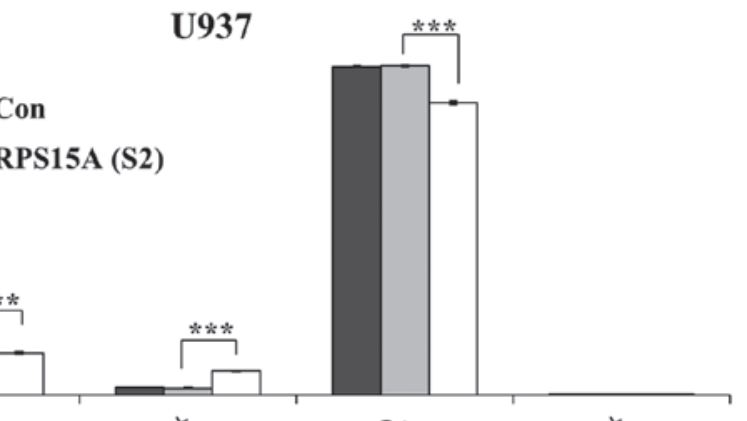

Figure 4. Effects of ribosomal protein S15a (RPS15A) knockdown on U937 cell apoptosis. Cell apoptosis was determined using flow cytometry. (A) Representative images of control (Con), short hairpin RNA (sh)Con and shRPS15A (S2) apoptosis, as determined by flow cytometry. (B) Proportion of each quadrant [Annexin V+/7-aminoactinomycin D (7-AAD)-, Annexin V+/7-AAD+, Annexin V-/7-AAD-, Annexin V-/7-AAD+]. Data are presented as the mean \pm standard deviation of three independent experiments. ${ }^{* * *} \mathrm{P}<0.001$, compared with the shCon group. Lv, lentivirus. 
Therefore, identification of novel therapeutic targets, and the development of novel therapeutic regimens that more effectively regulate cellular function are of central importance. RPS15A has been reported to be overexpressed and have an important role in regulating carcinogenesis in several types of human cancer. Elevation of RPS15A expression in tumor cells leads to phenotype changes that are characteristic of more aggressive malignancy $(20,22)$.

It has been reported that RPS15A gene expression was upregulated in leukemia tissues at the mRNA level (34-36). Furthermore, in order to ensure the specificity of RPS15A silencing, two RPS15A shRNA expression vectors were used, which resulted in a marked decrease in RPS15A expression in U937 cells. Knockdown of RPS15A inhibited proliferation of U937 cells, and led to cell cycle arrest at $G_{0} / G_{1}$ phase, as determined by flow cytometry. Notably, downregulation of RPS15A in hepatocellular carcinoma cells has previously been shown to potently suppress cell growth via cell cycle arrest at $\mathrm{G}_{0} / \mathrm{G}_{1}$ phase (22). The results of the present study also indicated that RPS15A may have a crucial role in regulating AML cell growth. In addition, the present study demonstrated that the majority of shRPS15A-transduced cells underwent apoptosis. These results strongly suggested that RPS15A may have a central role in AML carcinogenesis and the maintenance of malignant phenotypes. It may be hypothesized that RPS15A dysregulation may affect the translation of proteins that specifically govern the cell cycle. Therefore, the identification of RPS15A downstream target proteins through high-throughput proteomics is the focal point of our future research, which will facilitate the elucidation of the mechanisms underlying the effects of RPS15A on AML development.

In conclusion, to the best of our knowledge, this is the first study to examine the function of RPS15A in AML cells. The results demonstrated that inhibition of RPS15A significantly reduced U937 cell proliferation, and induced $G_{0} / G_{1}$ phase arrest and apoptosis, thus providing a future target for AML therapy. Further investigations regarding the regulatory mechanisms underlying the effects of RPS15A on AML may help to better understand AML carcinogenesis.

\section{Acknowledgements}

The authors of the present study are grateful for the financial support received from the National Natural Science Foundation of China (grant no. 81573772) and the Shandong Provincial Science and Technology Development Projects (grant no. 2014GSF118141).

\section{References}

1. Ferlay J, Soerjomataram I, Ervik M, Dikshit R, Eser S, Mathers C, Rebelo M, Parkin DM, Forman D and Bray F: GLOBOCAN 2012 v1.0, Cancer Incidence and Mortality Worldwide: IARC CancerBase No. 11 (Internet). International Agency for Research on Cancer, Lyon, France, 2013. http://globocan.iarc.fr. Accessed December 12, 2013.

2. Smith M, Barnett M, Bassan R, Gatta G, Tondini C and Kern W: Adult acute myeloid leukaemia. Crit Rev Oncol Hematol 50: 197-222, 2004.

3. Siegel RL, Miller KD and Jemal A: Cancer statistics, 2016. CA Cancer J Clin 66: 7-30, 2016.

4. Showel MM and Levis M: Advances in treating acute myeloid leukemia. F1000Prime Rep 6: 96, 2014.
5. Swords R, Freeman C and Giles F: Targeting the FMS-like tyrosine kinase 3 in acute myeloid leukemia. Leukemia 26: 2176-2185, 2012.

6. Döhner H, Estey EH, Amadori S, Appelbaum FR, Büchner T, Burnett AK, Dombret H, Fenaux P, Grimwade D, Larson RA, et al; European LeukemiaNet: Diagnosis and management of acute myeloid leukemia in adults: Recommendations from an international expert panel, on behalf of the European LeukemiaNet. Blood 115: 453-474, 2010.

7. Cornelissen JJ, van Putten WL, Verdonck LF, Theobald M, Jacky E, Daenen SM, van Marwijk Kooy M, Wijermans P, Schouten H, Huijgens PC, et al: Results of a HOVON/SAKK donor versus no-donor analysis of myeloablative HLA-identical sibling stem cell transplantation in first remission acute myeloid leukemia in young and middle-aged adults: Benefits for whom? Blood 109: 3658-3666, 2007.

8. Wu Q, Ding W, Mirza A, Van Arsdale T, Wei I, Bishop WR, Basso A, McClanahan T, Luo L, Kirschmeier P, et al: Integrative genomics revealed RAI3 is a cell growth-promoting gene and a novel P53 transcriptional target. J Biol Chem 280: 12935-12943, 2005.

9. Tan M, Wang Y, Guan K and Sun Y: PTGF-beta, a type beta transforming growth factor (TGF-beta) superfamily member, is a p53 target gene that inhibits tumor cell growth via TGF-beta signaling pathway. Proc Natl Acad Sci USA 97: 109-114, 2000.

10. Hiss D: Optimizing molecular-targeted therapies in ovarian cancer: The renewed surge of interest in ovarian cancer biomarkers and cell signaling pathways. J Onco 2012: 737981, 2012.

11. Lee SG, Su ZZ, Emdad L, Sarkar D, Franke TF and Fisher PB: Astrocyte elevated gene-1 activates cell survival pathways through PI3K-Akt signaling. Oncogene 27: 1114-1121, 2008.

12. Bouchet $\mathrm{S}$, Tang R, Fava F, Legrand $\mathrm{O}$ and Bauvois B: Targeting CD13 (aminopeptidase-N) in turn downregulates ADAM17 by internalization in acute myeloid leukaemia cells. Oncotarget 5: 8211-8222, 2014

13. Warner JR and McIntosh KB: How common are extraribosomal functions of ribosomal proteins? Mol Cell 34: 3-11, 2009.

14. Lavoie C, Tam R, Clark M, Lee H, Sonenberg N and Lasko P: Suppression of a temperature-sensitive cdc33 mutation of yeast by a multicopy plasmid expressing a Drosophila ribosomal protein. J Biol Chem 269: 14625-14630, 1994.

15. Piantoni P, Bionaz M, Graugnard DE, Daniels KM, Akers RM and Loor JJ: Gene expression ratio stability evaluation in prepubertal bovine mammary tissue from calves fed different milk replacers reveals novel internal controls for quantitative polymerase chain reaction. J Nutr 138: 1158-1164, 2008.

16. Akiyama N, Matsuo Y, Sai H, Noda M and Kizaka-Kondoh S: Identification of a series of transforming growth factor beta-responsive genes by retrovirus-mediated gene trap screening. Mol Cell Biol 20: 3266-3273, 2000.

17. Zeller KI, Jegga AG, Aronow BJ, O'Donnell KA and Dang CV: An integrated database of genes responsive to the Myc oncogenic transcription factor: Identification of direct genomic targets. Genome Biol 4: R69, 2003.

18. Katz JP, Perreault N, Goldstein BG, Actman L, McNally SR, Silberg DG, Furth EE and Kaestner KH: Loss of Klf4 in mice causes altered proliferation and differentiation and precancerous changes in the adult stomach. Gastroenterology 128: 935-945, 2005.

19. Whitney EM, Ghaleb AM, Chen X and Yang VW: Transcriptional profiling of the cell cycle checkpoint gene krüppel-like factor 4 reveals a global inhibitory function in macromolecular biosynthesis. Gene Expr 13: 85-96, 2006.

20. Lian Z, Liu J, Li L, Li X, Tufan NL, Wu MC, Wang HY, Arbuthnot P, Kew $M$ and Feitelson MA: Human S15a expression is upregulated by hepatitis B virus $\mathrm{X}$ protein. Mol Carcinog 40: 34-46, 2004.

21. Kavak E, Unlü M, Nistér M and Koman A: Meta-analysis of cancer gene expression signatures reveals new cancer genes, SAGE tags and tumor associated regions of co-regulation. Nucleic Acids Res 38: 7008-7021, 2010.

22. Xu M, Wang Y, Chen L, Pan B, Chen F, Fang Y, Yu Z and Chen G: Down-regulation of ribosomal protein S15A mRNA with a short hairpin RNA inhibits human hepatic cancer cell growth in vitro. Gene 536: 84-89, 2014.

23. Tiscornia G, Singer O and Verma IM: Production and purification of lentiviral vectors. Nat Protoc 1: 241-245, 2006.

24. Livak KJ and Schmittgen TD: Analysis of relative gene expression data using real-time quantitative PCR and the 2(-Delta Delta C(T)) Method. Methods 25: 402-408, 2001.

25. Deschler B and Lübbert M: Acute myeloid leukemia: Epidemiology and etiology. Cancer 107: 2099-2107, 2006. 
26. Sun K, Li Y, Lu Z, Zhang L, Gao Z and Jin Q: Suppression of titanium particle-induced TNF-alpha expression and apoptosis in human U937 macrophages by siRNA silencing. Int J Artif Organs 36: 522-527, 2013.

27. Yao K, Xing H, Yang W, Liao A, Wu B, Li Y, Zhang R and Liu Z: Knockdown of RLIP76 expression by RNA interference inhibits proliferation, enhances apoptosis, and increases chemosensitivity to daunorubicin in U937 leukemia cells. Tumour Biol 35: 8023-8031, 2014.

28. Long M, Hao M, Dong K, Shen J, Wang X, Lin F, Liu L, Wei J, Liang Y, Yang J, et al: AEG-1 overexpression is essential for maintenance of malignant state in human AML cells via up-regulation of Akt1 mediated by AURKA activation. Cell Signal 25: 1438-1446, 2013.

29. Bai Y, Qiu GR, Zhou F, Gong LY, Gao F and Sun KL: Overexpression of DICER1 induced by the upregulation of GATA1 contributes to the proliferation and apoptosis of leukemia cells. Int J Oncol 42: 1317-1324, 2013.

30. Gao H, Jiang Q, Han Y, Peng J and Wang C: shRNA-mediated EMMPRIN silencing inhibits human leukemic monocyte lymphoma U937 cell proliferation and increases chemosensitivity to adriamycin. Cell Biochem Biophys 71: 827-835, 2015.

31. Ye P, Zhao L, McGirr C and Gonda TJ: MYB down-regulation enhances sensitivity of U937 myeloid leukemia cells to the histone deacetylase inhibitor LBH589 in vitro and in vivo. Cancer Lett 343: 98-106, 2014.
32. Watanabe N, Narita M, Yamahira A, Taniguchi T, Furukawa T, Yoshida T, Miyazawa T, Nashimoto M and Takahashi M: Induction of apoptosis of leukemic cells by TRUE gene silencing using small guide RNAs targeting the WT1 mRNA. Leuk Res 37: 580-585, 2013.

33. Hu S, Chen R, Man X, Feng X, Cen J, Gu W, He H, Li J, Chai Y and Chen Z: Function and expression of insulin-like growth factor-binding protein 7 (IGFBP7) gene in childhood acute myeloid leukemia. Pediatr Hematol Oncol 28: 279-287, 2011.

34. Haferlach T, Kohlmann A, Wieczorek L, Basso G, Kronnie GT, Béné MC, De Vos J, Hernández JM, Hofmann WK, Mills KI, et al: Clinical utility of microarray-based gene expression profiling in the diagnosis and subclassification of leukemia: Report from the International Microarray Innovations in Leukemia Study Group. J Clin Oncol 28: 2529-2537, 2010.

35. Valk PJ, Verhaak RG, Beijen MA, Erpelinck CA, Barjesteh va n Waalwijk van Doorn-Khosrovani S, Boer JM, Beverloo HB, Moorhouse MJ, van der Spek PJ, Löwenberg B and Delwel R: Prognostically useful gene-expression profiles in acute myeloid leukemia. N Eng1 J Med 350: 1617-1628, 2004.

36. Andersson A, Ritz C, Lindgren D, Edén P, Lassen C, Heldrup J, Olofsson T, Råde J, Fontes M, Porwit-Macdonald A, et al: Microarray-based classification of a consecutive series of 121 childhood acute leukemias: Prediction of leukemic and genetic subtype as well as of minimal residual disease status. Leukemia 21: 1198-1203, 2007. 